\title{
Identification of microRNAs in the West Nile virus vector Culex tarsalis
}

\author{
Sultan Asad ${ }^{1}$, Ahmed M. Mehdi ${ }^{2}$, Sujit Pujari ${ }^{1,3}$, Claudia Rüeckert ${ }^{4,5}$, Gregory D. Ebel ${ }^{5}$, \\ and Jason L. Rasgon ${ }^{*}$
}

1. Department of Entomology, The Center for Infectious Disease Dynamics, and the Huck Institutes of the Life Sciences. The Pennsylvania State University, University Park, PA, USA

2. The University of Queensland, Brisbane, Australia Diamantina Institute, Faculty of Medicine, The University of Queensland, Translational Research Institute, Brisbane, QLD, Australia

3. Department of Pharmacology Physiology and Neuroscience, University of South Carolina School of Medicine, Columbia, South Carolina, USA

4. Department of Biochemistry and Molecular Biology, University of Nevada Reno, Reno, NV, 89557, USA

5. Center for Vector-borne Infectious Diseases, Department of Microbiology, Immunology and Pathology, College of Veterinary Medicine and Biomedical Sciences, Colorado State University, Fort Collins, CO 80523, USA

${ }^{*}$ Corresponding Author: Jason L. Rasgon, phone number 814-863-3668, fax 814-8653048, email 16 address ilr54@psu.edu 


\section{Abstract}

Background: microRNAs (miRNAs) represent a group of small non-coding RNAs that are crucial gene regulators of important biological functions including development and pathogen defense in most living organisms. Presently, there is a lack of availability of information regarding the miRNAs in the mosquito Culex tarsalis, which is one of the most important vectors of West Nile virus (WNV) in the United States. We used small RNA sequencing data and in vitro and in vivo experiments to identify and validate the presence of a repertoire of miRNAs in $C x$. tarsalis mosquitoes.

Results: Using bioinformatic approaches we analyzed small RNA sequencing data from the $C x$. tarsalis CT embryonic cell line to discover 86 miRNAs. Consistent with other mosquitoes such as Aedes albopictus and Cx. quinquefasciatus, mi-184 was found to be the most abundant miRNA in $C x$ tarsalis. We also identified an additional 20 novel miRNAs from the recently sequenced $C x$. tarsalis genome, for a total of 106 miRNAs identified in this study. The presence of selected miRNAs was biologically validated in both cell line and adult $C x$. tarsalis mosquitoes using RT-qPCR and sequencing.

Conclusions: $C x$. tarsalis is an important vector of many medically important pathogens including WNV and Western Equine encephalitis. Here we report a detailed insight into the miRNA population in $C x$. tarsalis mosquitoes. These results will open new avenues of research deciphering the role of miRNAs in different $C x$. tarsalis biological events such as development, metabolism, immunity and pathogen infection. 


\section{Background}

Recent reports of the involvement of miRNAs in insect immunity and host-pathogen interactions have highlighted the need for investigating miRNAs in mosquitoes that have significant impacts on global health. miRNAs are small non-coding RNAs ranging from 19-25 nucleotides in length which regulate post transcriptional gene expression [1, 2]. In the animal kingdom, miRNAs regulate gene expression by binding imperfectly to the mRNAs either at the 3'-untranslated regions (3'-UTR), 5'-untranslated regions (5'-UTR), or coding regions. Though the 2-8 nucleotides at the 5' end of the miRNA ("seed region") perfect complementarity to the target transcript is integral for miRNA function, the rest of the miRNA sequence can have mismatches and bulges $[1,3,4]$. miRNAs are transcribed inside the nucleus into a primary miRNA transcript which is processed into a pre-miRNA by Drosha and Pasha. The pre-miRNA is then exported to the cytoplasm with the help of exportin proteins. Once in cytoplasm, the pre-miRNA is processed by Dicer I into the $\sim 22$ nucleotide mature miRNA. Once maturation is completed the mature miRNA is loaded into the microRNA induced silencing complex (miRISC) where it becomes single-stranded. The single-stranded miRNA-miRISC complex then targets the mRNA with sequence similarity leading to target mRNA degradation or modulation of protein expression $[5,6]$. miRNAs are critical for a variety of cellular processes including development [7], immunity [8] and pathogen response [9, 10], which make them an interesting choice to investigate in the host pathogen interactions of vector mosquitoes and the medically important pathogens they carry.

More than 3000 mosquito species are present worldwide, but many important mosquito species are underrepresented in miRbase (a database of all miRNAs reported from 
different species) [11]. Recent advances in sequencing platforms and bioinformatic approaches have allowed us to successfully identify the miRNAs from species whose genomes are not yet properly sequenced, assembled and annotated.

Cx. tarsalis is a neglected yet important vector of many medically important viruses such as WNV [12-14], West Equine Encephalitis (WEEV) [15], St. Louis Encephalitis (SLEV) [16] and Cache Valley virus (CVV) [17] in North America. Despite many studies focusing on the ecology, feeding behavior and vector competence of this mosquito, there is little information regarding miRNAs in $C x$. tarsalis. Here we have mined and analyzed publicly available small RNA sequencing data of the $C x$. tarsalis $C T$ cell line to identify 86 high confidence miRNAs that are present in $C x$ tarsalis mosquitoes. Ten randomly chosen miRNAs were confirmed both in-vitro and in-vivo in mosquitoes.

\section{Results and Discussion}

\section{Data Used in this study}

We accessed publicly available small RNA data generated from the $C x$. tarsalis CT cell line and passed it through our in-house pipeline (Figure 1) to identify miRNAs, using CLC genomic work bench 20. SRA read files described in Figure $2 A$ were directly downloaded into CLC genomics workbench. All reads were trimmed by removing the RA3 adapter (TGGAATTCTCGGGTGCCAAGGG) sequences from the 3' end of raw sequencing reads. Any reads with low quality scores or that did not have an adapter sequence were excluded. After removal of the RA3 adapter sequences we saw a cluster of RNA sequences ranging from 21-24 nucleotides with the highest peak at 22 
nucleotides which is the most abundant size of mosquito miRNAs (Figure $2 \mathrm{~B}$ ). In order to further examine the profile of the trimmed RNA reads, we used the web-based server sRNA toolbox [18] to determine that approximately 70 percent of the reads were mappable to miRbase (Figure 2C).

\section{Discovery of miRNAs in Cx tarsalis}

miRNAs have been demonstrated to play a pivotal role in insect development [7, 19], reproduction [20, 21], metabolism and longevity [22, 23], insecticide resistance [24, 25], immunity, and host-pathogen interactions [26, 27], and have been shown to govern processes relevant to public health in various mosquito species [28-30]. Using CLC genomic workbench 20 we annotated and mapped trimmed small RNA reads from 3 biological replicates from the $C x$. tarsalis CT cell line to mature miRNAs of both $A e$. aegypti and $C x$. quinquefasciatus using default parameters. miRNAs discovered were considered to be true hits only if they were present in at least two out of three biological replicates. Our analysis found 60 and 84 mature miRNAs in $C x$. tarsalis using $C x$. quinquefasciatus (Figure 3A) and Ae. aegypti (Figure 3B) mature miRNAs as reference, respectively, with a 58 mature miRNA overlap using Jvenn online server (figure 3C, Supplementary table 1) [31]. Finally, we successfully identified a total of 86 high confidence miRNAs in Cx. tarsalis mosquitoes (Table 1).

\section{Majority of Cx. tarsalis miRNAs arise from the 3' arm and sequence variations occur mostly at 3' arm of mature miRNAs}


Mature miRNAs are formed as a result of a Dicer-mediated processing of precursor miRNA (pre-miRNA) having two arms/strands named $5 p$ and $3 p$, leading to selective loading and retention of either $3 p$ or $5 p$ in the miRISC complex to become functionally active, while the other strand is cleaved out of the complex and degraded [5]. This strand selection has been demonstrated to be influenced by the thermodynamic instability of the duplex, 5' end starting nucleotides, and miRNA duplex length [32-34]. In our results we were able to detect mature miRNA that arose from $5 p, 3 p$ and both $5 p$ and $3 p$ of pre-miRNAs. Our data showed that 49 out of 86 miRNAs identified in this study were derived from the $3^{\prime}$ arm of the pre-miRNA which indicates that in the $C x$. tarsalis CT cell line, there may be a preference toward $3 p$ arm processing of miRNAs (Figure 4A). However, this finding needs further experimental validation.

In each of the data libraries used in this study, adapter trimmed small RNA reads mapped to the reference sequences of mature miRNAs from miRbase showed variability. These variants with slight difference in length and sequence are commonly known as isomiRs. These isomiRs are usually produced due to imperfect processing/cleavage by Drosha or Dicer [35-37]. IsomiRs were long considered as an artifact, but recent advances in deep sequencing and computational algorithms have identified isomiRs in many species [38-40], including in Ae. aegypti [41]. IsomiRs are classified into three main categories: $5^{\prime}$ isomiRs, 3' isomiRs, and polymorphic isomiRs with 5' and 3' isomiRs subclassified according to the nucleotide's insertions and deletions [42]. To find out and quantify the miRNA isomiRs, we used CLC Genomic workbench 20 to quantify the isomiRs based on nucleotide additions, insertions and substitutions. We focused on insertions and deletions of nucleotides at 3 ' or 5' of mature 
miRNAs and limited our discovery to 2 nucleotide addition or deletion at the either end. IsomiRs that were present in all three biological replicates were used for analysis (Supplementary table 2). Our results show most modifications occurring at the 3' end of the mature miRNAs, in particularly 2 nucleotide insertion followed by the 1 nucleotide insertion (Figure 4B). Our results agree with previous studies that highlighted majority of sequence variations leading to isomiRs formation are at the 3' end of mature miRNAs [43]. Although the 5' variations are rare, they have more evolutionary and functional importance, as most of the 5' variations lead to a shift in the seed region that might affect regulatory ability of the miRNA [44]. Expanded analysis revealed that cta-miR-184 showed a total of 240 different types of isomiRs, followed by cta-miR-2940-3p that showed 161 different types of isomiRs. Although both cta-miR-184 and cta-miR-2940$3 p$ showed the highest amount of isomiRs formation, there was a striking difference in the modification pattern as the former showed the majority of sequence variations at the 3' end (Figure 4C) while the later showed the highest amount of sequence variations at the 5 ' end (Figure 4D). These results warrant further investigation into the role of isomiRs in mosquito physiology and host pathogen interactions, for example in the case of WNV infections.

\section{Validation of $C x$. tarsalis miRNAs}

We randomly selected 10 miRNAs: cta-miR-317-3p, cta-miR-7, cta-miR-999, cta-miR71-3p, cta-miR-33, cta-miR-2940-5p, cta-miR-998, cta-miR-92b-3p, cta-miR-2951-5p and cta-miR-2945 for validation both in vitro (CT cell line) and in-vivo in 7 day old sugar fed female Cx. tarsalis mosquitoes (Figure 5A, B). All qPCR amplicons were cloned into 
PJET and mature miRNA sequences confirmed through Sanger sequencing (Supplementary Figure 1).

\section{Prediction and validation of novel miRNAs from the $C x$. tarsalis genome}

During the preparation of this manuscript, the Cx. tarsalis genome was published [45], which we used to identify novel miRNAs (present in all 3 replicates) that could be mapped to the $C x$. tarsalis genome. Our results identified 20 novel miRNAs in $C x$. tarsalis mosquitoes (Table 2). RNAfold (rna.tbi.univie.ac.at/cgibin/RNAWebSuite/RNAfold.cgi) was used to determine the secondary structure of the predicted pre-miRNA sequences (Figure 6). Primers were designed for 12 randomly selected novel miRNAs and validated through RT-qPCR in both the CT cell line and Cx. tarsalis mosquitoes. Our results confirm that all 12 novel selected miRNAs were expressed in CT cells (Figure 7A), but in mosquitoes we were only able to detect 8 out of 12 (Figure 7B), likely reflecting physiological differences between cultured cells and live mosquitoes.

\section{Conclusions}

Our study has identified a total of 106 miRNAs, including 86 already reported in other mosquitoes, and 20 novel miRNAs that are present in the $C x$. tarsalis genome. These results will lay the foundation for functional studies and open new avenues for research in $C x$. tarsalis biology and pathogen transmission. 


\section{Methods}

\section{Small RNA libraries and data analysis}

To identify $C x$. tarsalis miRNAs we have used publicly available small RNA data of $C x$. tarsalis CT cell line [46] from National Center for Biotechnology Information Sequence Read archive. A total of 3 libraries were downloaded. All libraries were generated using the TruSeq Small RNA Sample Prep Kit (Illumina) and sequenced on the Illumina HiSeq 2000 platform. The data were analyzed using CLC genome workbench 20. Libraries were trimmed of adapter sequences and the trimmed libraries were mapped to known miRNAs and miRNAs star strands of Ae. aegypti and $C x$. quinquefasciatus. For novel miRNA prediction the miRDeep2 pipeline was used [47].

\section{Mosquitoes and cell lines}

Cx. tarsalis mosquitoes (YOLO strain) were reared at $26{ }^{\circ} \mathrm{C}$ with $40-50 \%$ relative humidity and a 16:8 hr light and dark cycle. The mosquitoes were provided with 10\% sucrose solution ad libitum. The $C x$. tarsalis cell line CT (generously provided by $\mathrm{Dr}$ Aaron Brault, $\mathrm{CDC}$ ) was maintained at $28{ }^{\circ} \mathrm{C}$ with $0.5 \% \mathrm{CO}_{2}$ in Schneider medium supplemented with $10 \%$ of fetal bovine serum (GIBCO) and 1\% antibiotics (GIBCO). Cells were passaged once per week. 
Qiazol was used to extract total RNA from both cells and mosquitoes following the manufacturer's suggested protocol. For mosquito RNA samples, 5 Cx. tarsalis sugar fed females (7 days old) were pooled per biological replicate. RNA was quantified using a Nanodrop and 2ug of total RNA was used to synthesize miRNA cDNA using the miScript RT kit following manufacturer's suggested protocol. cDNA was 10 times diluted and approximately $18 \mathrm{ng}$ of cDNA was used to validate miRNAs identified in this study using the miScript qPCR kit according to manufacturer's suggested protocol. All qPCR reactions were performed with 3 biological replicates and 2-3 technical replicates. U6 RNA was used as internal control for RT-qPCR. CT values were imported into Qiagen qPCR data analysis excel template to get normalized expression values.

\section{Cloning and sequencing of miRNA amplicons}

qPCR amplicons were seperated using $1 \%$ agarose gel electrophoresis. Single amplicon bands were cut using a sterile surgical blade and DNA was extracted with the Zymo Gel extraction kit according to manufacturer's suggested protocol. Eluted amplicons were directly cloned in to pJET1.2/Blunt vector according to manufacturer's suggested protocol. Positive clones were sent to GENEWIZ for Sanger sequencing. Sequencing data was analyzed with CLC genomic workbench 20. 


\section{Figure Legends}

Figure 1. Schematic diagram of miRNA discovery pipeline Diagram showing use of an integrated approach of bioinformatics and wet laboratory experiments to identify $C x$. tarsalis miRNAs.

Figure 2. Small RNA sequencing data A) Culex tarsalis small RNA data used in this study. B) Read length distribution after the adapter removal showed enrichment of reads around 21-24 nucleotides confirming the successful removal of adapter sequences. C) RNA profile of reads after adapter removal showing around 70 percent of read mapped to miRbase.

Figure 3. Identification of $C x$ tarsalis miRNAs A) Venn diagram of miRNAs identified across 3 biological replicates. B) Venn diagram showing common miRNAs identified within 3 biological replicates. C) Overlap of miRNAs identified with Ae. aegypti and Cx. quinquefasciatus annotation. D) 10 most abundant miRNAs in $C x$. tarsalis RNA samples, each bar represents average normalized expression value of individual miRNA, error bars represent the standard deviation, and the dots shows the values of individual biological replicates.

Figure 4. Cx. tarsalis miRNA mostly arise from $3 p$ arm having most of sequence variation at 3'end of miRNA A) Number of miRNAs processed from either $3 p$ or $5 p$ 
arm of pre-miRNA. B) Overall sequence variations at 3' or 5' of mature miRNA sequences. C) Sequence variation found in cta-miR-184 showing most of the variations at the 3' end of the mature miRNA. D) Sequence variation found in cta-miR-2940-3p showing most of the variations at the 5' end of the mature miRNA.

Figure 5. Validation of $\boldsymbol{C x}$. tarsalis miRNAs. Primer extension-based confirmation of 10 randomly selected miRNAs with RT-qPCR using 3 biological replicates. U6 was used as reference for relative quantification. Graphs showing relative expression of ctamiRNAs/U6 in A) CT cell line B) Cx. tarsalis female mosquitoes. Error bars represent standard deviation and dots represent individual biological replicate values. Each biological replicate is made up of $5 C x$. tarsalis sugar fed 7 days old females.

Figure 6. Prediction of secondary structure of novel miRNAs. Stem-loop structures of predicted novel pre-miRNAs. Mature novel miRNAs are highlighted in red while their corresponding strand are highlighted in blue/magenta.

Figure 7. Validation of novel $\boldsymbol{C x}$ tarsalis miRNAs. RT-qPCR based amplification of novel miRNAs in A) CT cells and B) $C x$. tarsalis female mosquitoes. Error bars represent standard deviation and dots represent individual biological replicate values. Each biological replicate is made up of 5 sugar fed $C x$. tarsalis 7 day old females. 
bioRxiv preprint doi: https://doi.org/10.1101/2021.09.23.461553; this version posted September 24,2021 . The copyright holder for this preprint (which was not certified by peer review) is the author/funder, who has granted bioRxiv a license to display the preprint in perpetuity. It is made available under aCC-BY-NC 4.0 International license.

\section{Acknowledgements}

This work was supported by NIH grants R01Al15025, R01Al128201, and R01Al116636 to JLR. We are thankful to $\mathrm{Dr}$ Aaron C. Brault from CDC for generously providing the CT cell line. 


\section{References}

1. Bartel DP: MicroRNAs: target recognition and regulatory functions. Cell 2009, 136(2):215-233.

2. Bartel DP, Chen CZ: Micromanagers of gene expression: the potentially widespread influence of metazoan microRNAs. Nat Rev Genet 2004, 5(5):396-400.

3. Rigoutsos I: New tricks for animal microRNAS: targeting of amino acid coding regions at conserved and nonconserved sites. Cancer Res 2009, 69(8):3245-3248.

4. Schnall-Levin M, Zhao $Y$, Perrimon N, Berger B: Conserved microRNA targeting in Drosophila is as widespread in coding regions as in 3'UTRs. Proc Natl Acad Sci U S A 2010, 107(36):15751-15756.

5. Asgari S: Chapter Two - microRNAs as Regulators of Insect Host-Pathogen Interactions and Immunity. In: Advances in Insect Physiology. Edited by Smagghe G, vol. 55: Academic Press; 2018: 19-45.

6. Flynt AS, Greimann JC, Chung WJ, Lima CD, Lai EC: MicroRNA biogenesis via splicing and exosome-mediated trimming in Drosophila. Mol Cell 2010, 38(6):900-907.

7. Alvarez-Garcia I, Miska EA: MicroRNA functions in animal development and human disease. Development 2005, 132(21):4653-4662.

8. Momen-Heravi F, Bala S: miRNA regulation of innate immunity. $J$ Leukoc Biol 2018. 
9. Miesen $\mathrm{P}$, Ivens $\mathrm{A}$, Buck $\mathrm{AH}$, van Rij RP: Small RNA Profiling in Dengue Virus 2-Infected Aedes Mosquito Cells Reveals Viral piRNAs and Novel Host miRNAs. PLoS Negl Trop Dis 2016, 10(2):e0004452.

10. Saldana MA, Etebari K, Hart CE, Widen SG, Wood TG, Thangamani S, Asgari S, Hughes GL: Zika virus alters the microRNA expression profile and elicits an RNAi response in Aedes aegypti mosquitoes. PLoS Negl Trop Dis 2017, 11(7):e0005760.

11. Kozomara A, Birgaoanu M, Griffiths-Jones S: miRBase: from microRNA sequences to function. Nucleic Acids Res 2019, 47(D1):D155-D162.

12. Goddard LB, Roth AE, Reisen WK, Scott TW: Vector competence of California mosquitoes for West Nile virus. Emerg Infect Dis 2002, 8(12):1385-1391.

13. Goldberg TL, Anderson TK, Hamer GL: West Nile virus may have hitched a ride across the Western United States on Culex tarsalis mosquitoes. Mol Ecol 2010, 19(8):1518-1519.

14. Venkatesan M, Broman KW, Sellers M, Rasgon JL: An initial linkage map of the West Nile Virus vector Culex tarsalis. Insect Mol Biol 2009, 18(4):453-463.

15. Barnett HC: The transmission of Western equine encephalitis virus by the mosquito Culex tarsalis Coq. Am J Trop Med Hyg 1956, 5(1):86-98.

16. Hammon WM, Reeves WC: Laboratory Transmission of St. Louis Encephalitis Virus by Three Genera of Mosquitoes. J Exp Med 1943, 78(4):241-253. 
17. Ayers VB, Huang YS, Lyons AC, Park SL, Higgs S, Dunlop JI, Kohl A, Alto BW, Unlu I, Blitvich BJ et al: Culex tarsalis is a competent vector species for Cache Valley virus. Parasit Vectors 2018, 11(1):519.

18. Aparicio-Puerta E, Lebrón R, Rueda A, Gómez-Martín C, Giannoukakos S, Jaspez D, Medina JM, Zubkovic A, Jurak I, Fromm B, Marchal JA, Oliver J, \& Hackenberg M: sRNAbench and sRNAtoolbox 2019: intuitive fast small RNA profiling and differential expression. Nucleic Acids Research 2019, 47(W1), W530-W535.

19. Zhang Y, Zhou X, Ge X, Jiang J, Li M, Jia S, Yang X, Kan Y, Miao X, Zhao G et al: Insect-Specific microRNA Involved in the Development of the Silkworm Bombyx mori. PLoS One 2009, 4(3):e4677.

20. Song J, Li W, Zhao H, Gao L, Fan Y, Zhou S: The microRNAs let-7 and miR278 regulate insect metamorphosis and oogenesis by targeting the juvenile hormone early-response gene Krüppel-homolog 1. Development 2018, 145(24):dev170670.

21. Zhang Q, Dou W, Pan D, Chen EH, Niu JZ, Smagghe G, Wang JJ: GenomeWide Analysis of MicroRNAs in Relation to Pupariation in Oriental Fruit Fly. Front Physiol 2019, 10:301.

22. Ling L, Kokoza VA, Zhang C, Aksoy E, Raikhel AS: MicroRNA-277 targets insulin-like peptides 7 and 8 to control lipid metabolism and reproduction in Aedes aegypti mosquitoes. Proceedings of the National Academy of Sciences 2017, 114(38):E8017-E8024. 
23. Ma K-S, Li F, Liu Y, Liang P-Z, Chen X-W, Gao X-W: Identification of microRNAs and their response to the stress of plant allelochemicals in Aphis gossypii (Hemiptera: Aphididae). BMC Molecular Biology 2017, 18(1):5.

24. Li X, Guo L, Zhou X, Gao X, Liang P: miRNAs regulated overexpression of ryanodine receptor is involved in chlorantraniliprole resistance in Plutella xylostella (L.). Scientific Reports 2015, 5(1):14095.

25. Etebari K, Afrad MH, Tang B, Silva R, Furlong MJ, Asgari S: Involvement of microRNA miR-2b-3p in regulation of metabolic resistance to insecticides in Plutella xylostella. Insect Mol Biol 2018, 27(4):478-491.

26. Saldaña MA, Etebari K, Hart CE, Widen SG, Wood TG, Thangamani S, Asgari S, Hughes GL: Zika virus alters the microRNA expression profile and elicits an RNAi response in Aedes aegypti mosquitoes. PLOS Neglected Tropical Diseases 2017, 11(7):e0005760.

27. Wong RR, Abd-Aziz N, Affendi S, Poh CL: Role of microRNAs in antiviral responses to dengue infection. Journal of Biomedical Science 2020, 27(1):4.

28. Dubey SK, Shrinet J, Sunil S: Aedes aegypti microRNA, miR-2944b-5p interacts with 3'UTR of chikungunya virus and cellular target vps-13 to regulate viral replication. PLOS Neglected Tropical Diseases 2019, 13(6):e0007429.

29. Yan H, Zhou Y, Liu Y, Deng Y, Chen X: miR-252 of the Asian tiger mosquito Aedes albopictus regulates dengue virus replication by suppressing the expression of the dengue virus envelope protein. J Med Virol 2014, 86(8):1428-1436. 
30. Slonchak A, Hussain M, Torres S, Asgari S, Khromykh AA: Expression of Mosquito MicroRNA Aae-miR-2940-5p Is Downregulated in Response to West Nile Virus Infection To Restrict Viral Replication. Journal of Virology 2014, 88(15):8457-8467.

31. Bardou P, Mariette J, Escudié F, Djemiel C, Klopp C: jvenn: an interactive Venn diagram viewer. BMC Bioinformatics 2014, 15(1):293.

32. Czech B, Hannon GJ: Small RNA sorting: matchmaking for Argonautes. Nat Rev Genet 2011, 12(1):19-31.

33. Han BW, Hung JH, Weng Z, Zamore PD, Ameres SL: The 3'-to-5' exoribonuclease Nibbler shapes the $3^{\prime}$ ends of microRNAs bound to Drosophila Argonaute1. Curr Biol 2011, 21(22):1878-1887.

34. Lucas K, Raikhel AS: Insect microRNAs: biogenesis, expression profiling and biological functions. Insect Biochem Mol Biol 2013, 43(1):24-38.

35. Kuchenbauer F, Morin RD, Argiropoulos B, Petriv OI, Griffith M, Heuser M, Yung E, Piper J, Delaney A, Prabhu AL et al: In-depth characterization of the microRNA transcriptome in a leukemia progression model. Genome Res 2008, 18(11):1787-1797.

36. Starega-Roslan J, Krol J, Koscianska E, Kozlowski P, Szlachcic WJ, Sobczak K, Krzyzosiak WJ: Structural basis of microRNA length variety. Nucleic Acids Res 2011, 39(1):257-268.

37. Wu $\mathrm{H}, \mathrm{Ye} \mathrm{C}$, Ramirez $\mathrm{D}$, Manjunath $\mathrm{N}$ : Alternative processing of primary microRNA transcripts by Drosha generates $5^{\prime}$ end variation of mature microRNA. PLoS One 2009, 4(10):e7566. 
38. Wyman SK, Knouf EC, Parkin RK, Fritz BR, Lin DW, Dennis LM, Krouse MA, Webster PJ, Tewari M: Post-transcriptional generation of miRNA variants by multiple nucleotidyl transferases contributes to miRNA transcriptome complexity. Genome Res 2011, 21(9):1450-1461.

39. Lee LW, Zhang S, Etheridge A, Ma L, Martin D, Galas D, Wang K: Complexity of the microRNA repertoire revealed by next-generation sequencing. RNA 2010, 16(11):2170-2180.

40. Amsel D, Vilcinskas A, Billion A: Evaluation of high-throughput isomiR identification tools: illuminating the early isomiRome of Tribolium castaneum. BMC Bioinformatics 2017, 18(1):359.

41. Etebari K, Osei-Amo S, Blomberg SP, Asgari S: Dengue virus infection alters post-transcriptional modification of microRNAs in the mosquito vector Aedes aegypti. Sci Rep 2015, 5:15968.

42. Neilsen CT, Goodall GJ, Bracken CP: IsomiRs--the overlooked repertoire in the dynamic microRNAome. Trends Genet 2012, 28(11):544-549.

43. Newman MA, Mani V, Hammond SM: Deep sequencing of microRNA precursors reveals extensive 3' end modification. RNA 2011, 17(10):17951803.

44. Tan GC, Chan E, Molnar A, Sarkar R, Alexieva D, Isa IM, Robinson S, Zhang S, Ellis $\mathrm{P}$, Langford CF et al: $\mathbf{5}^{\prime}$ isomiR variation is of functional and evolutionary importance. Nucleic Acids Res 2014, 42(14):9424-9435.

45. Main BJ, Marcantonio M, Rasgon JL, Brown CT, Barker CM: Whole genome assembly of Culex tarsalis. G3 Genes/Genomes/Genetics 2021, 11(2):jkaa063. 
46. Rückert C, Prasad AN, Garcia-Luna SM, Robison A, Grubaugh ND, WegerLucarelli J, Ebel GD: Small RNA responses of Culex mosquitoes and cell lines during acute and persistent virus infection. Insect Biochem Mol Biol 2019, 109:13-23.

46. Friedlander MR, Mackowiak SD, Li N, Chen W, Rajewsky N: miRDeep2 accurately identifies known and hundreds of novel microRNA genes in seven animal clades. Nucleic Acids Res 2012, 40(1):37-52. 
bioRxiv preprint doi: https://doi.org/10.1101/2021.09.23.461553; this version posted September 24, 2021. The copyright holder for this preprint (which was not certified by peer review) is the author/funder, who has granted bioRxiv a license to display the preprint in perpetuity. It is made available under aCC-BY-NC 4.0 International license.

Table 1.86 miRNAs identified by homology to Ae. aegypti and $C x$. quinquefasciatus. 
bioRxiv preprint doi: https://doi.org/10.1101/2021.09.23.461553; this version posted September 24, 2021. The copyright holder for this preprint (which was not certified by peer review) is the author/funder, who has granted bioRxiv a license to display the preprint in perpetuity. It is made available under aCC-BY-NC 4.0 International license.

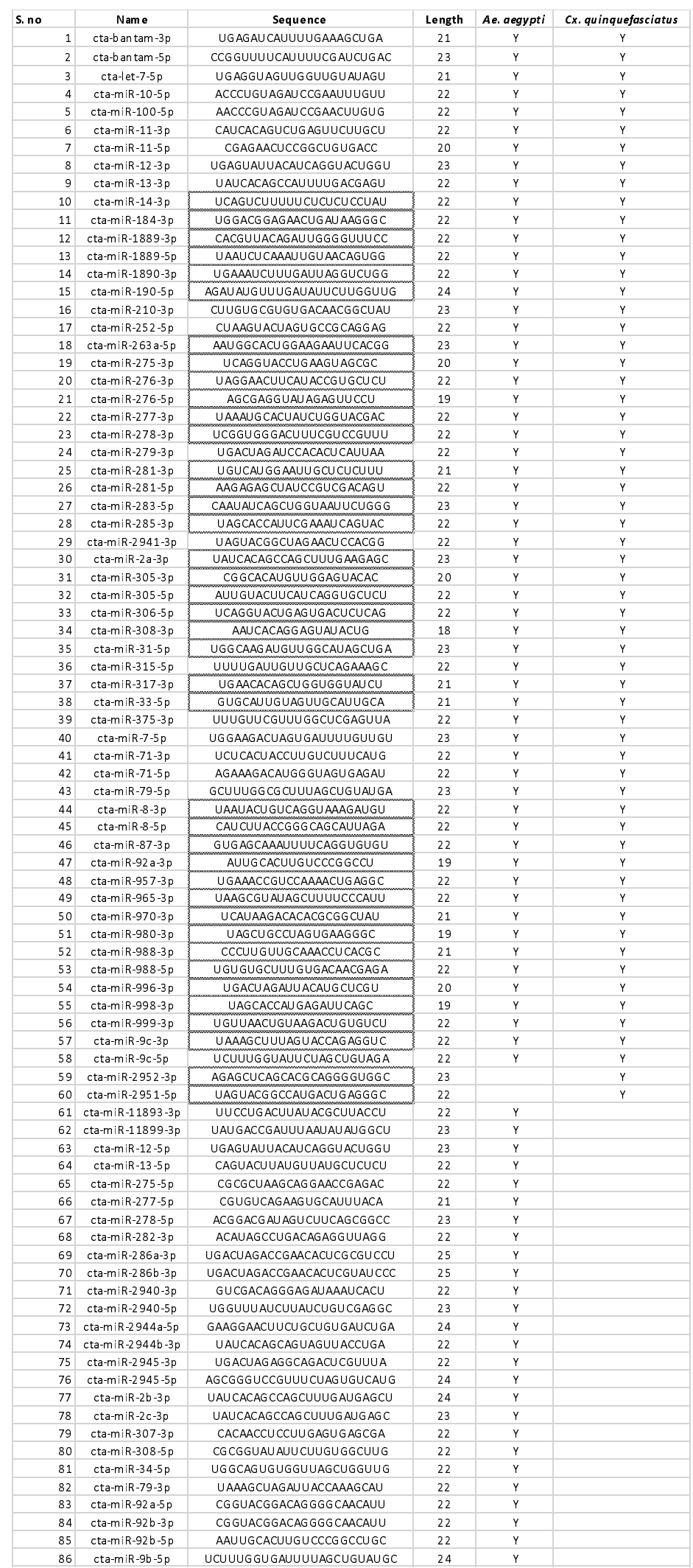

Table 2. Novel miRNAs identified from the $C x$. tarsalis genome. 
bioRxiv preprint doi: https://doi.org/10.1101/2021.09.23.461553; this version posted September 24, 2021. The copyright holder for this preprint (which was not certified by peer review) is the author/funder, who has granted bioRxiv a license to display the preprint in perpetuity. It is made available under aCC-BY-NC 4.0 International license.

\begin{tabular}{|c|c|c|}
\hline S. no & Name & Sequence \\
\hline 1 & cta-n ovel-1 & UUAACAAUAUUUGUGUGACCUG \\
\hline 2 & cta-n ovel-2 & UGACUAGAGGCAGACUCGUUU \\
\hline 3 & cta-n ovel-3 & UUUUAGACCGGUUUUGAACAC \\
\hline 4 & cta-n ovel-4 & AGAUAGGACCUUUUGAAAAAGU \\
\hline 5 & cta-n ovel-5 & AUGGCGCUGUAAAAAAGCUUUUU \\
\hline 6 & cta-n ovel-6 & UAUGCUAUCUUGGGACAUGUCU \\
\hline 7 & cta-n ovel-7 & CAUGAUAUCUUGUGACAUGUCU \\
\hline 8 & cta-n ovel-8 & AGCCGGACAGCCUCGACCUGGA \\
\hline 9 & cta-novel-9 & GAAGGAACUUCUGCUGUGAUCU \\
\hline 10 & cta-novel-10 & UGACUAGACCGAACACUCGUAUC \\
\hline 11 & cta-novel-11 & UAUGACCGAAUUAAUGUAUGGCU \\
\hline 12 & cta-novel-12 & UUCCUGACUUAUACGCUUACCCCU \\
\hline 13 & cta-novel-13 & UGUAACCCGUCAUGAACUGUCA \\
\hline 14 & cta-novel-14 & CAAACCGGAAGUUGUAAACUGU \\
\hline 15 & cta-novel-15 & AUCCCUGCCUUCGGAUGCCUA \\
\hline 16 & cta-novel-16 & UAUGCUAUCGUGUGACAUGUCU \\
\hline 17 & cta-novel-17 & UUUCGUUCCGGACACAAAAAUC \\
\hline 18 & cta-novel-18 & UCUACCGAUCGAUCUUCAUAGC \\
\hline 19 & cta-novel-19 & AACAAAGCCGAUCGGAAAAGU \\
\hline 20 & cta-novel-20 & GUAGAAUCGCGUCAAAUCGACUGA \\
\hline
\end{tabular}

Length Predicted Consensus Precursor Sequence UUAACAAUAUUUGUGUGACCUGUUGUUAAUACGAUAUGAAG GUCACACGAAUAUUGCUAAGU AGCGGGUCCGUUUCUAGUGUCAUGUGCUACGUUUGAAAGUCAUGACUAGAGGCAGACUCGUUU UGUUCAAAACCGGUCUAAAACGUGAUUUUUCCGUUUUAGACCGGUUUUGAACAC

UUUUUCAAAAGAUCCCAUCUGCUAUGGGUUUUCUAUGCAGAUAGGACCUUUUGAAAAAGU AAAGCUUUACACAACGCCAUCUAUCAGAAAAACUUAAUGACAAUCAGAUGGCGCUGUAAAAAAGCUUUUU UAUGCUAUCUUGGGACAUGUCUGCUGUAAAAAGAUAGGACGUGUCACAAGAUAGCACACA CAUGAUAUCUUGUGACAUGUCUGCUGUAAAAAGAUAGGACGUGUCACAAGAUAGCACA AGCCGGACAGCCUCGACCUGGACUACGACAUGUGGCAGGGCCAGUUCGAGUUUGUCGGGCCGGC GAAGGAACUUCUGCUGUGAUCUGAGAUGUGUUCAUAUCACAGUAGUUGUACUUUAA

GGCGAUUGUCGGCUUGGUCGCUGUCUUUACCCAAGGCACAGUUGCACUUCAGUGACUAGACCGAACACUCGUAUC CCAUAUAUGAUUUUGGUCAUAUAUUGAAUUAUGAUAUUUUAUAUGACCGAAUUAAUGUAUGGCU GUAAGUAGAUAAUUCAGAAAGGCGGCAACGUUUCUUCCUGACUUAUACGCUUACCCCU UGUAACCCGUCAUGAACUGUCAAAUUGGUGAAGCAGUUUGACAGUUCUUGUUGGGUUACAUU AGUUCAUCAUUUCCGGUUUGAUAGAGGAAUCAAACCGGAAGUUGUAAACUGU AAAGAGGUAGGGAUAACUCGCCAUCCCUGCCUUCGGAUGCCUA UAUGCUAUCGUGUGACAUGUCUGCUGUAAAAAAAUAGGACGUGUCACAAGAUAGCACUCA UUUCGUUCCGGACACAAAAAUCAGGAAUCGGCCUGAGGAUUUUUGUUUCCGGAAUGUCCACAGAAC CGUGAAGAUCUUCCGGUGCAGACAGGCUCGUUGAGGCCACUCAAAGUCACCAGCGUGUCUACCGAUCGAUCUUCAUAGC UUUUUCGUCGGCAGUGGCCAGUGUG AGAUACGCGCAACAAAGCCGAUCGGAAAAGU 
Figure 1

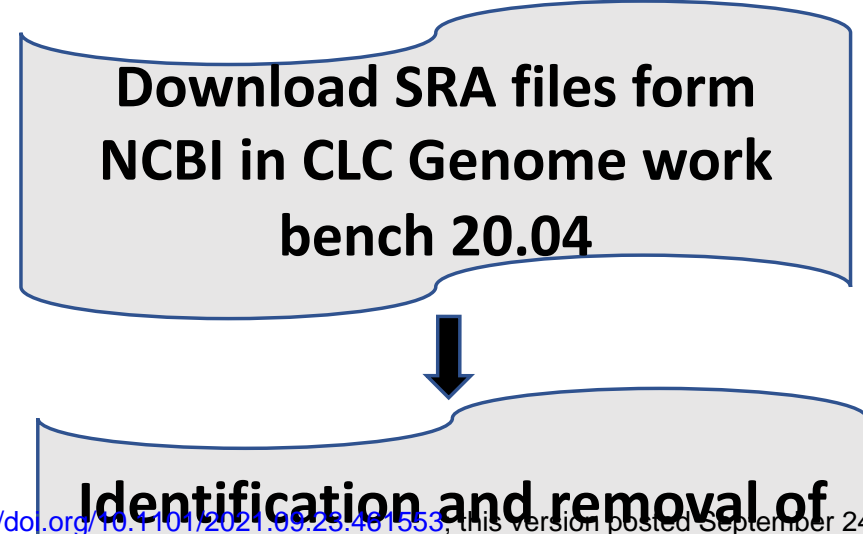
(which was not certified by peer review) is the author/funder, who has granted bioRxiv a license to display the preprint in perpetuity. It is

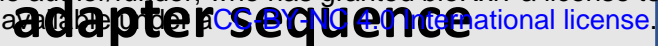

Discard sequences with less than 5 reads

Discard reads without Adapter sequence

Annotate Trimmed reads with miRbase 22.1 with Culex quinquefasciatus mature miRNAs as reference
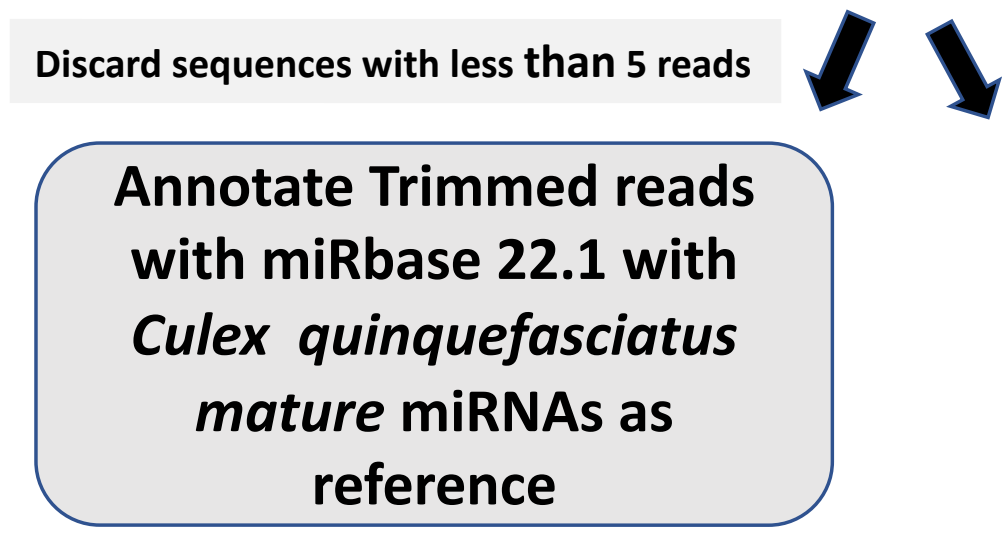

Annotate Trimmed reads with miRbase 22.1 with Aedes aegypti mature miRNAs as reference

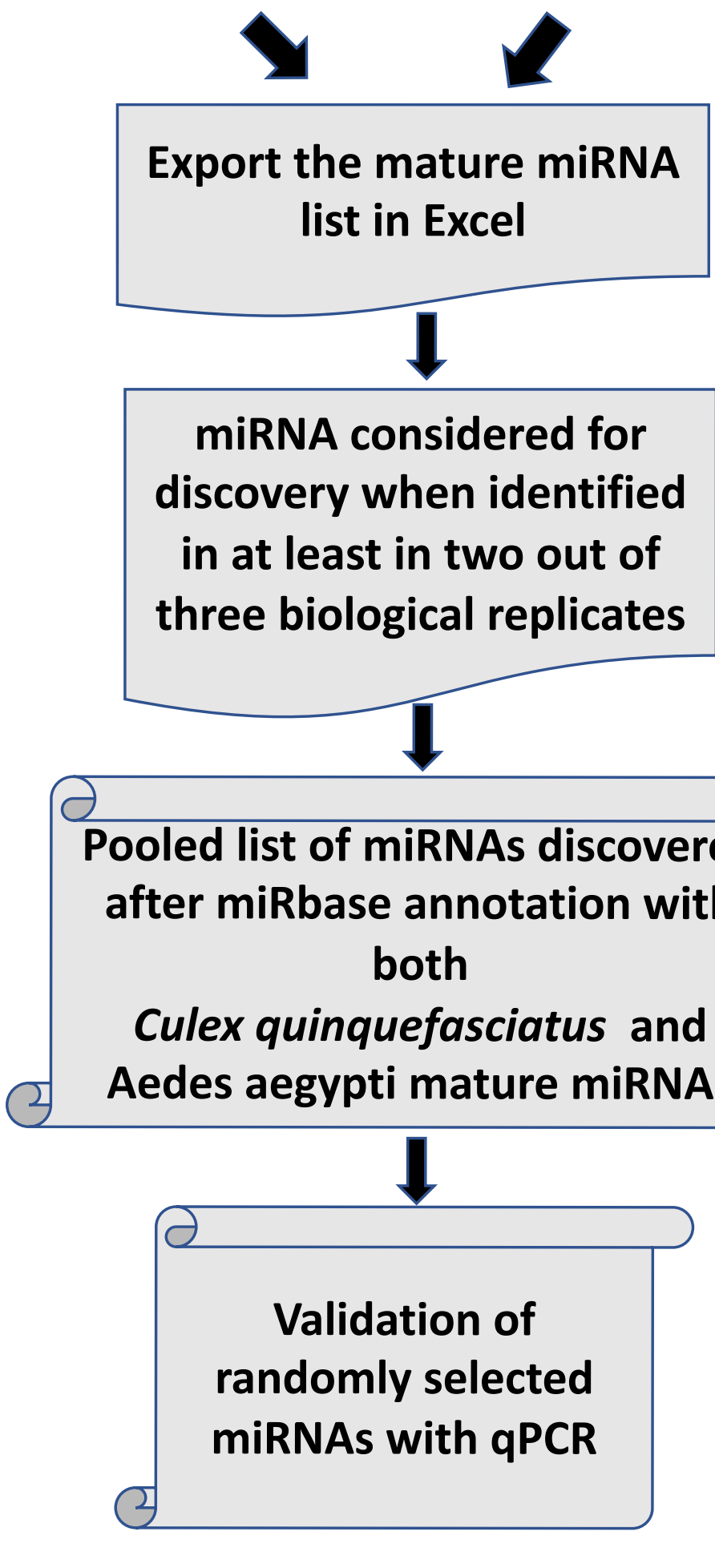


Figure 2

A

\begin{tabular}{|c|c|c|c|}
\hline \multicolumn{1}{|c|}{ SRA ID } & \multicolumn{1}{|c|}{ Sample } & Raw Reads & Number of Bases in millions \\
\hline SRR8936281 & Mock infected CT cells 2dpi rep1 & 8808220 & 669.4 \\
\hline SRR8936288 & Mock infected CT cells 2dpi rep2 & 6848904 & 520.4 \\
\hline SRR8936289 & Mock infected CT cells 2dpi rep3 & 7797739 & 197.7 \\
\hline
\end{tabular}

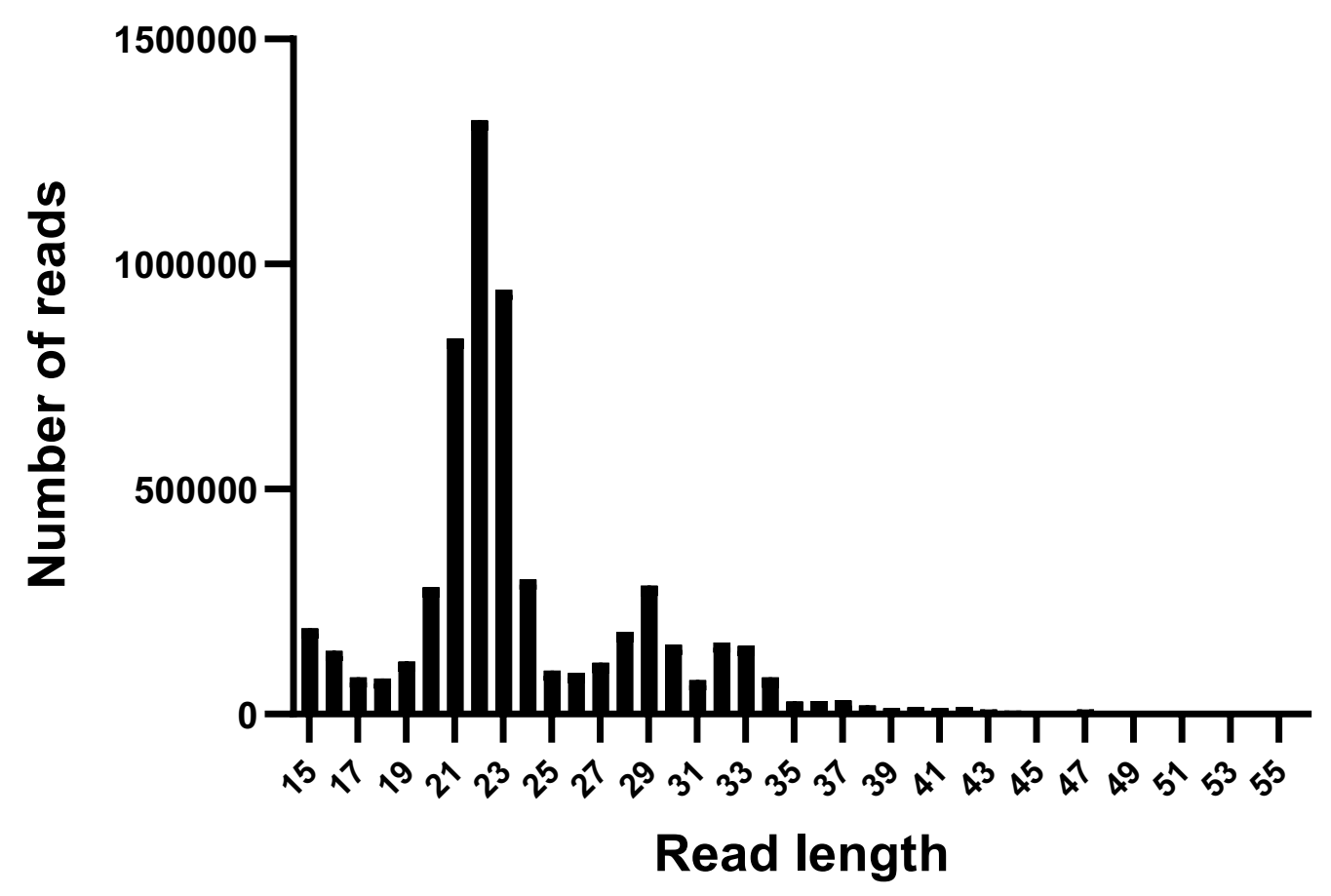

Read length
C

RNA Profile

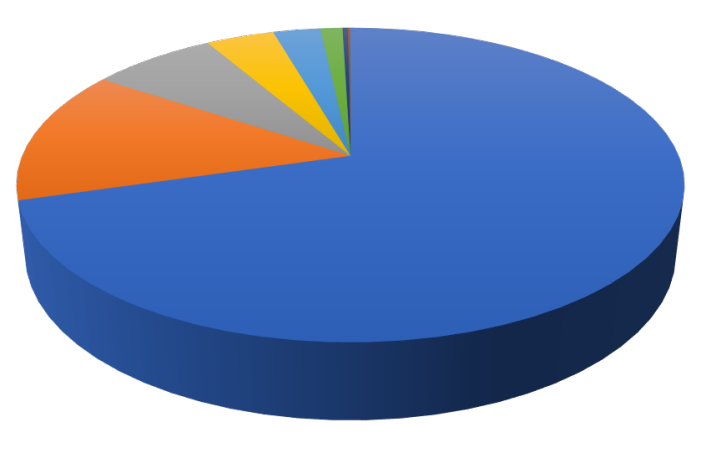
miRbase (sense)
- Unassigned
- rRNA
tRNA
mRNA (sense)
mRNA (Antisense)
— Other RNAs
- snoRNA
- snRNA 


\section{Culex quinquefasciatus}

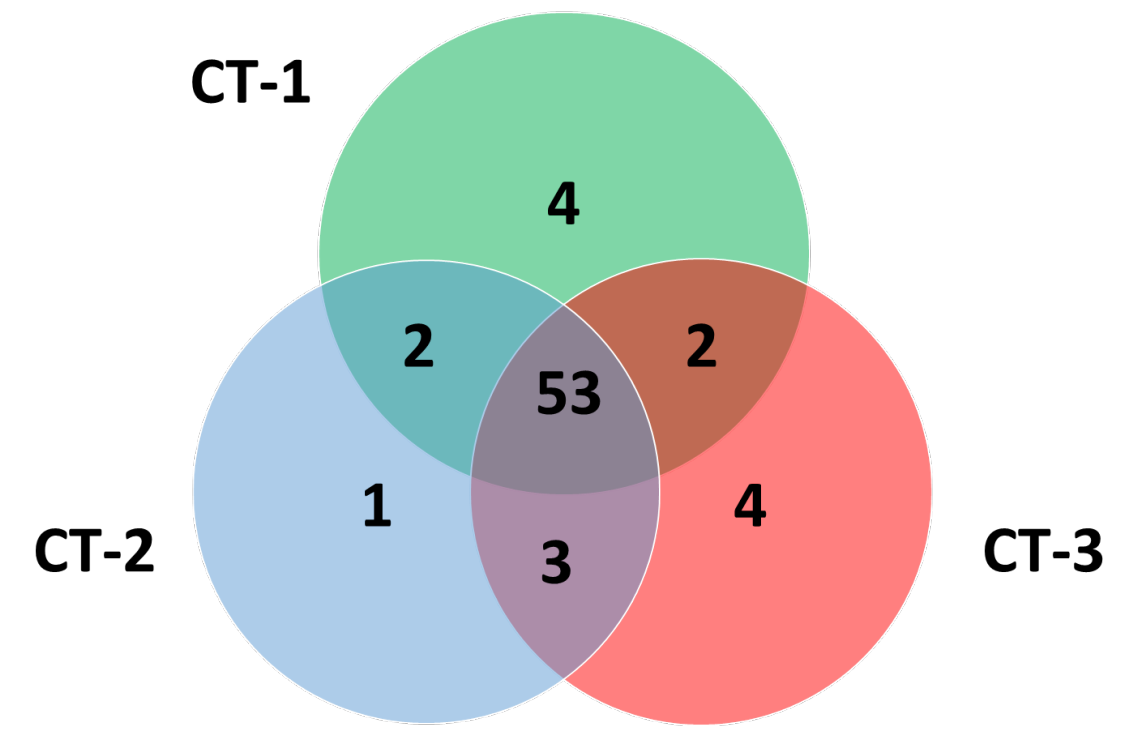

C Overlap between miRNAs identified with Aedes and Culex as reference

Aedes aegypti

Culex quinquefasciatus

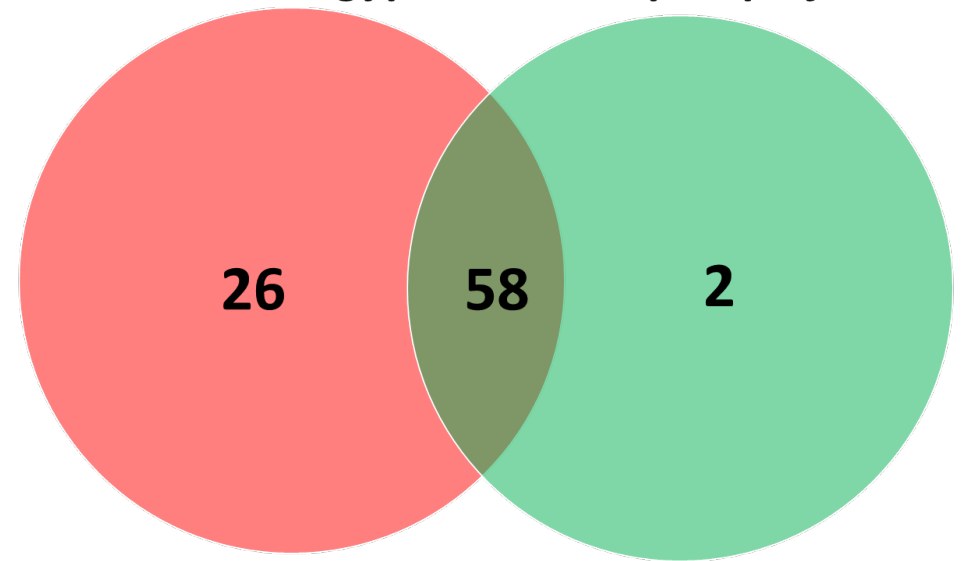

\section{Aedes aegypti}

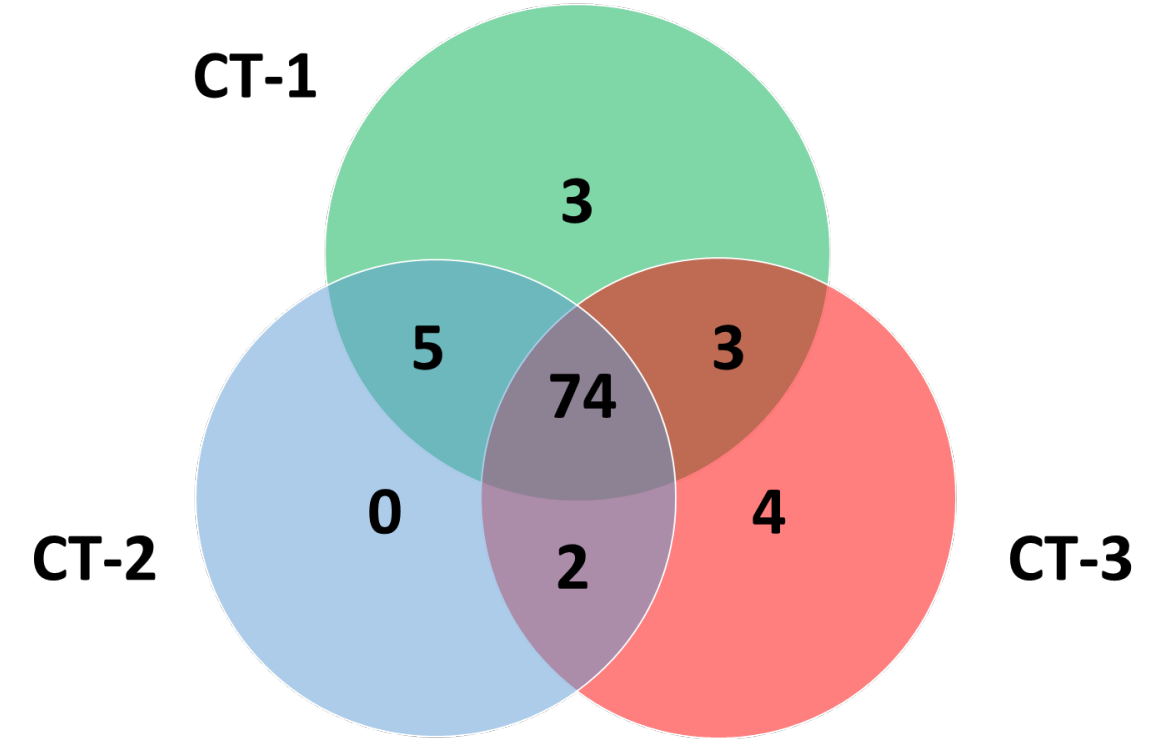

D

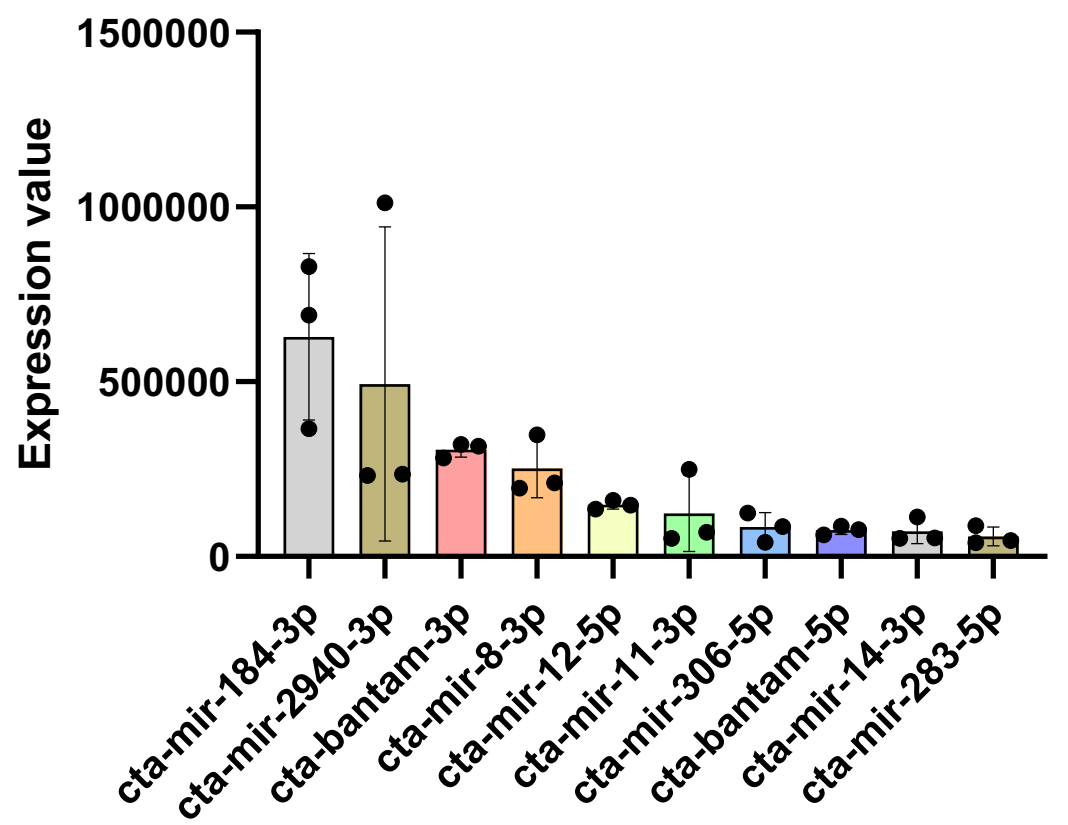


Figure 4

A

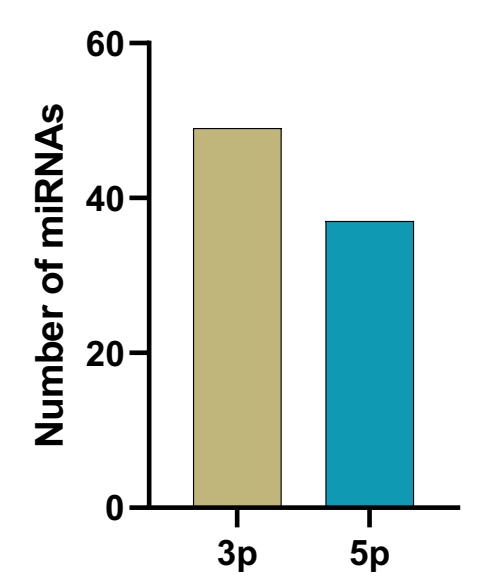

C

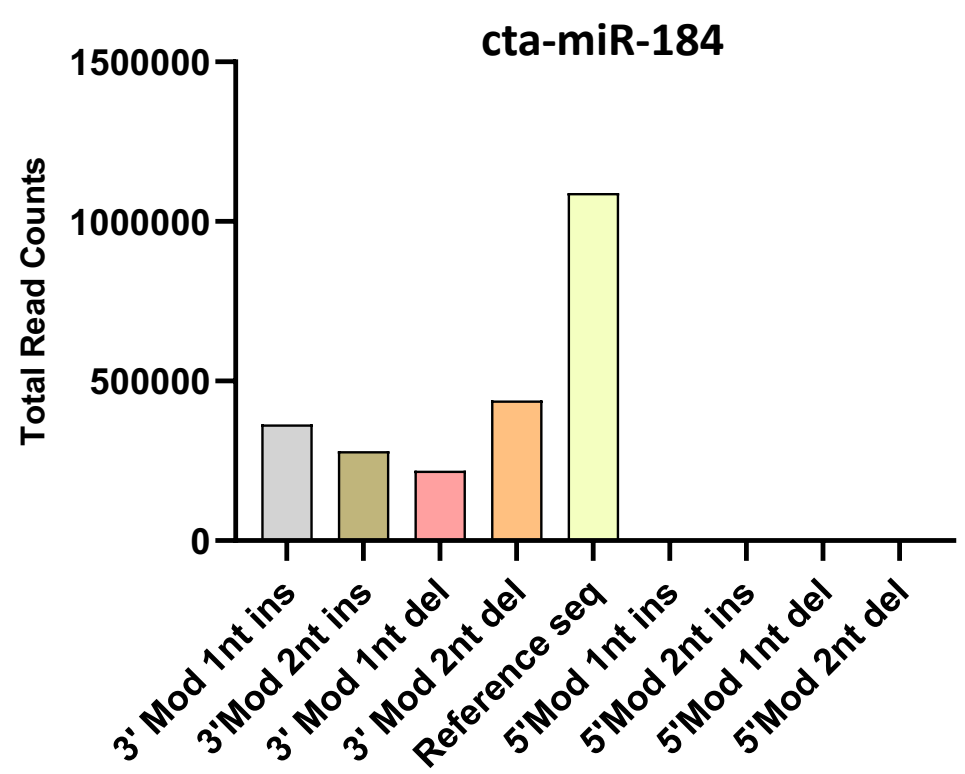

B

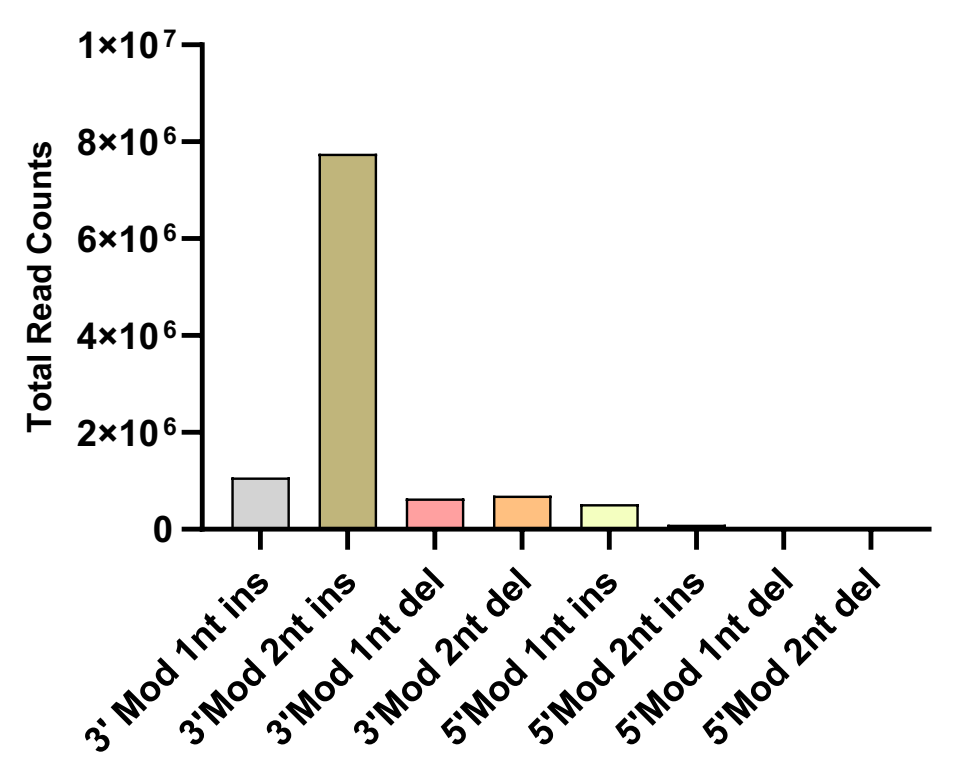

D

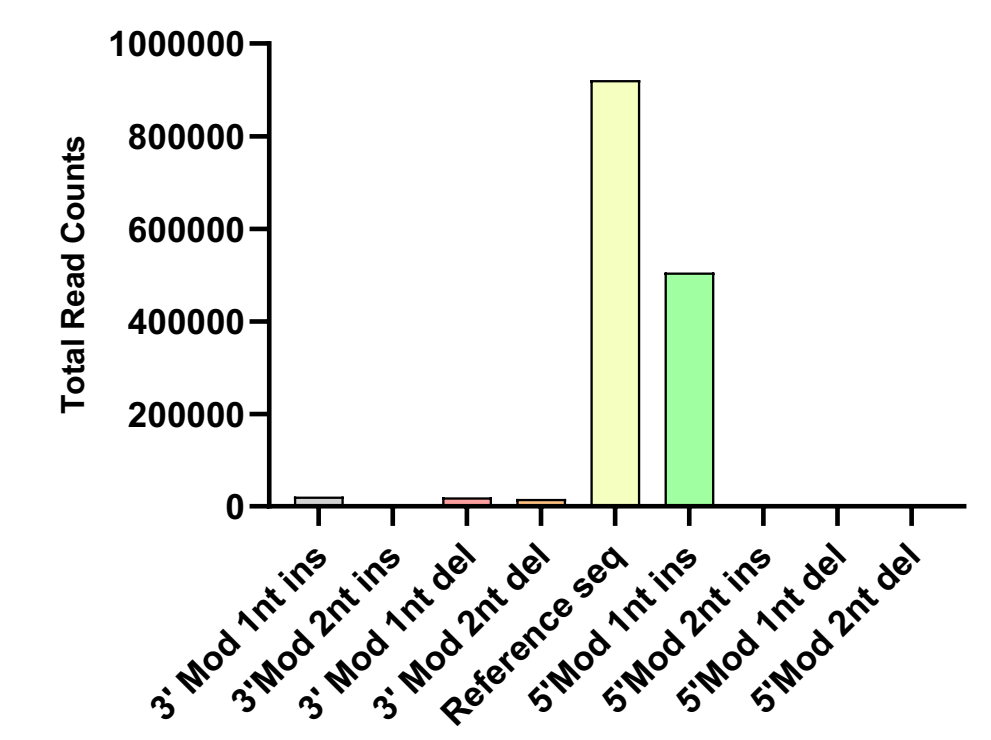


CT cell line

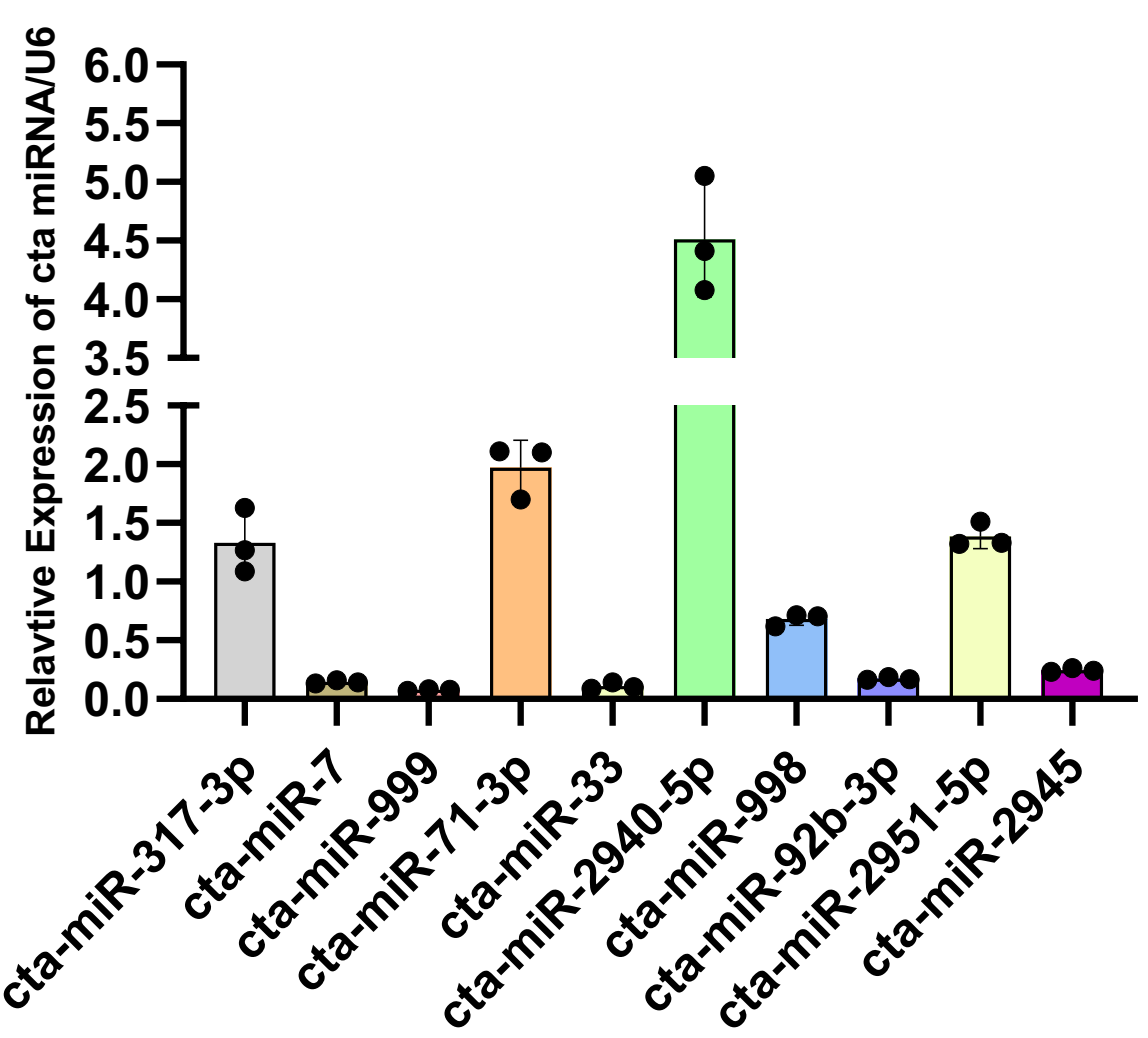

Cx. tarsalis female mosquitoes

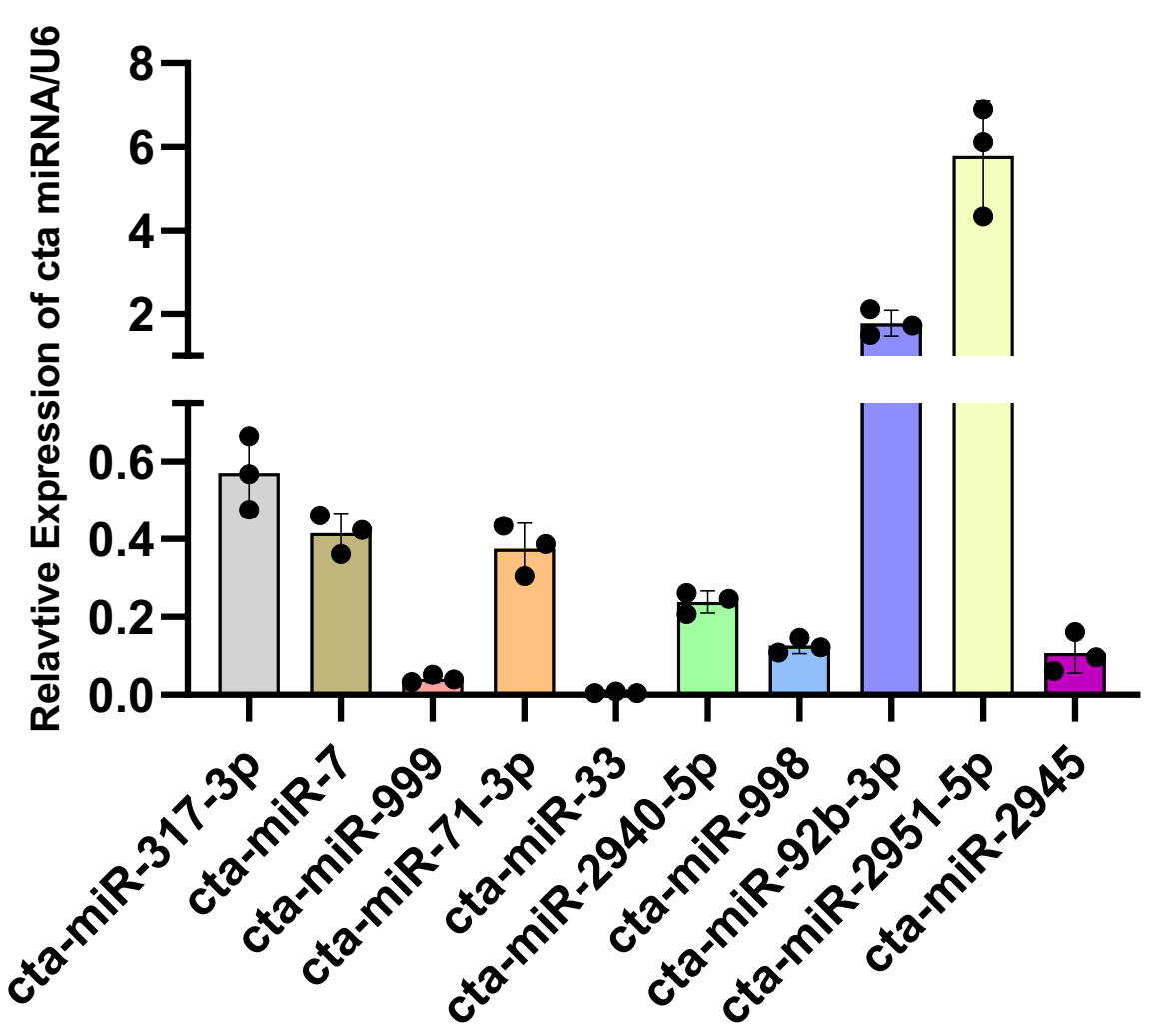


Figure 6

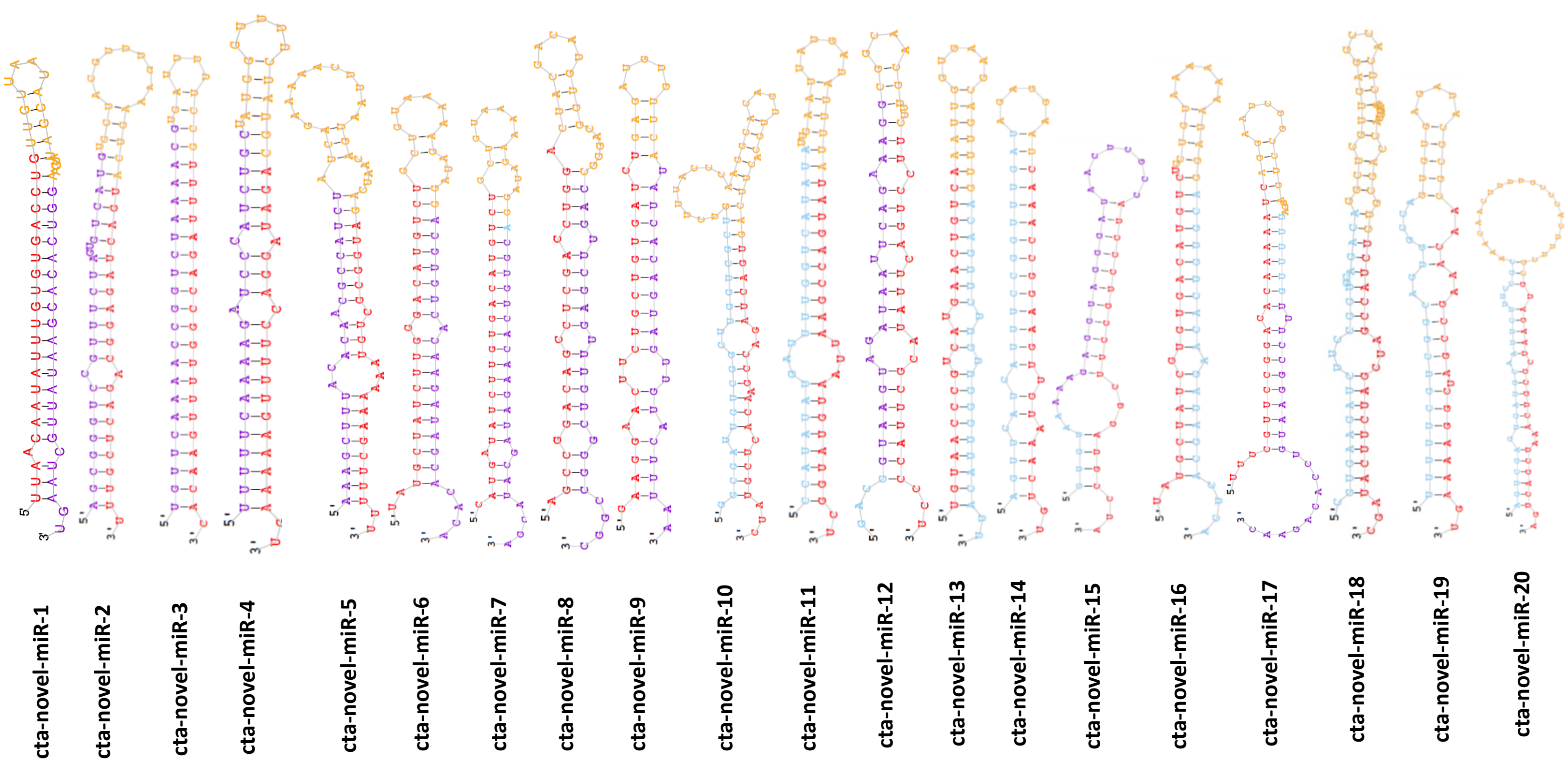


CT cell line

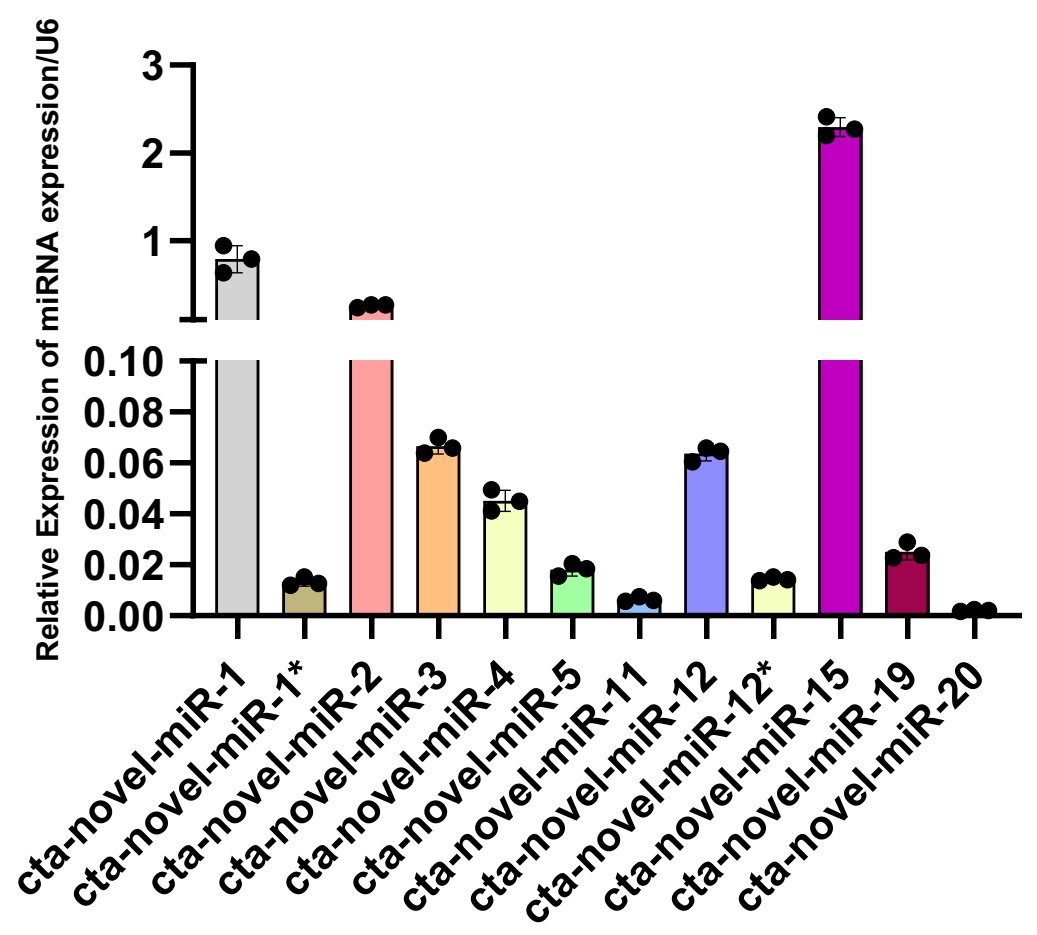

Cx. tarsalis female mosquitoes

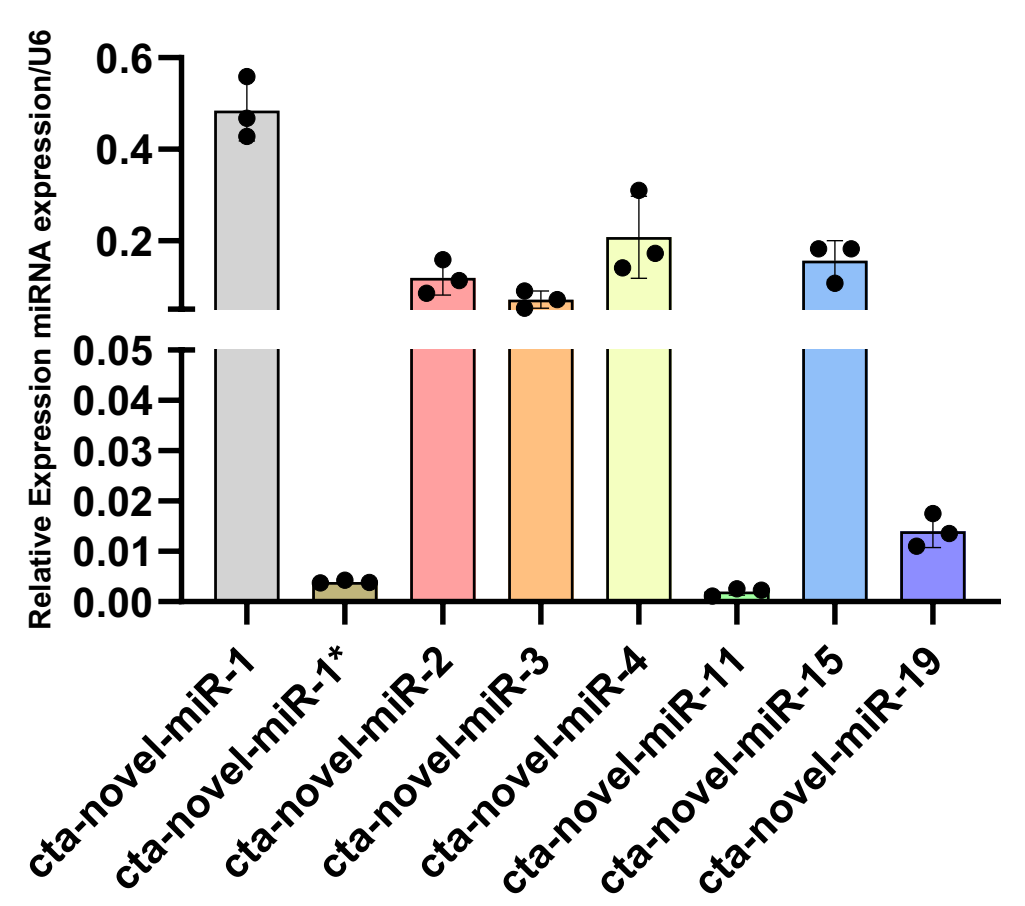

